\title{
A História da Ciência (Distorcida ou Ausente) em Livros Didáticos: O Conteúdo sobre o "Experimento de Torricelli" como Estudo de Caso ${ }^{1}$
}

\author{
The History of Science (Distorted or Absent) in Textbooks: The \\ Content on the "Torricelli Experiment" as a Case Study
}

\author{
Juliana M. Hidalgo ${ }^{\text {; }}$ Jardes M. Alves ${ }^{\text {; }}$ Fábio de A. Souza ${ }^{\text {; }}$ Daniel de M. Queiroz ${ }^{\mathrm{a}}$ \\ a Departamento de Física Teórica e Experimental, Universidade Federal do Rio Grande do Norte, Natal, Brasil - \\ juliana_hidalgo@yahoo.com, jardes777@hotmail.com, faabioabreu@hotmail.com,daniel.dmq@gmail.com
}

\section{Palavras-chave:}

Livros didáticos. História da ciência. Experimento de Torricelli. Pressão atmosférica.

Resumo: Esse trabalho apresenta uma pesquisa direcionada à avaliação crítica da História da Ciência presente em livros didáticos brasileiros. Particularmente, o objetivo dessa pesquisa foi contribuir para a compreensão de como os elementos relacionados ao processo de construção histórica do conceito de pressão atmosférica aparecem nos livros didáticos. São discutidos especificamente os resultados da análise realizada de acordo com os seguintes critérios: fundamentos historiográficos atuais; apontamentos da legislação educacional para a inserção didática da História da Ciência, fontes primárias e secundárias da História da Ciência relacionadas ao desenvolvimento do conceito de pressão atmosférica. Dentre os problemas notados destacam-se o anacronismo, a pseudohistória, visões simplistas sobre a ciência, a ausência de explicações sustentadas por pensadores do passado e uma abordagem (totalmente) descontextualizada do experimento de Torricelli.

Keywords:

School books. History of science. Torricelli's experiment. Atmospheric pressure.

\begin{abstract}
This paper presents research referring to History of Science in Brazilian school books. Particularly, our goal was to contribute to the understanding of the way elements related to the process of historical construction of the concept of atmospheric pressure appear in school books. This work discusses specifically the results from the analyses accomplished according to the following criteria: historiographical concerns, Brazilian educational documents, primary and secondary sources in History of Science related to the development of the concept of atmospheric pressure. Some problems were noticed such as anachronism, pseudohistory, näive views regarding Nature of Science, the absence of explanations supported by past thinker and a (totally) decontextualized approach to Torricelli's experiment.
\end{abstract}

${ }^{1}$ Os autores agradecem aos pareceristas pelos comentários e sugestões.

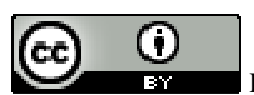

Esta obra foi licenciada com uma Licença Creative Commons Atribuição 4.0 Internacional 


\section{Introdução}

Costuma-se promover no contexto escolar a visão de que o desenvolvimento do conhecimento científico ocorre sem controvérsias. São focalizados apenas os produtos da ciência. O cientista é tratado como um gênio alheio ao contexto social. É obscurecido o papel da criatividade. A ciência apresentada na escola é:

[...] fragmentada em pacotes fechados à argumentação, ao questionamento e à dúvida, procedimento através do qual teorias e leis científicas passam a ser divulgadas como se fossem dogmas, ou então como se fossem mágica, surgida "do nada", ou da manga dos cientistas (GOULART, 2005, p. 1).

Os estudantes permanecem alheios ao "porquê", ao "para quê" do conhecimento científico, e são levados por uma visão instrumental do conhecimento: estudar para obter notas. Apresentar uma ciência pronta e acabada pouco contribui para a formação de um cidadão crítico que venha a atuar ativamente na sociedade (GIL-PÉREZ et al., 2001; GUERRA, 2014).

Um objetivo central do ensino escolar deveria ser "formar cidadãos capazes de estabelecer uma relação crítica com a ciência e a tecnologia, [...] conhecedores da História da Ciência" (DUARTE, 2004, p. 318). Esses aspectos são reforçados pela legislação brasileira atualmente em vigor para o ensino de Física, bem como pela Base Nacional Curricular, foco recente de discussão:

Espera-se que o ensino de Física, na escola média, contribua para a formação de uma cultura científica efetiva [...] é essencial que o conhecimento físico seja explicitado como um processo histórico, objeto de contínua transformação e associado às outras formas de expressão e produção humanas (BRASIL, parte III, 2000, p. 24).

O ensino de Ciências da Natureza tem compromisso com uma formação que prepare o sujeito para interagir e atuar [...]; a alfabetização e o letramento científicos; a compreensão de como a ciência se constituiu historicamente e a quem ela se destina [...] (BRASIL, 2015, p. 149).

Saber Física e sobre a Física contribui para entender e posicionar-se criticamente frente a questões tecnocientíficas da atualidade que envolvem diversos interesses e grupos sociais (BRASIL, 2015, p. 205).

De acordo com essa perspectiva, propostas pedagógicas não devem ser exclusivamente focalizadas nos produtos da ciência:

Um tratamento didático apropriado é a utilização da história e da filosofia da ciência para contextualizar o problema, sua origem e as tentativas de solução que levaram à proposição de modelos teóricos, a fim de que o aluno tenha noção de que houve um caminho percorrido para se chegar a esse saber (BRASIL, 2006, p. 50).

$\mathrm{Na}$ literatura especializada no ensino de disciplinas científicas, não é recente a afirmação de que englobar o processo de construção do conhecimento pode: 
[...] tomar as aulas de ciências mais desafiadoras e reflexivas, permitindo, deste modo, o desenvolvimento do pensamento crítico; [...] contribuir para um entendimento mais integral de matéria científica (MATTHEWS, 1995, p. 165).

Advoga-se a favor da presença permanente e fundamental da História e Filosofia da Ciência no contexto escolar. Trata-se de uma perspectiva não meramente ilustrativa ou como introdução acessória aos conteúdos (MARTINS, 2007; GUERRA, 2014). Segundo Matthews (1994, p. 50), “a compreensão dos conhecimentos físicos está intrinsicamente relacionada ao entendimento dos problemas a que tais conhecimentos buscaram responder".

\section{Historiografia da Ciência e legislação educacional}

[...] o conhecimento da historicidade das ciências promove a independência da mente, evitando o "cientismo", isto é, a exaltação das ciências como algo absoluto, como uma capacidade quase ilimitada na resolução dos problemas da humanidade. [...] combate também o dogmatismo, evitando que se julguem como ingênuas as teorias científicas de outras épocas vistas à luz dos dados e das ideias de hoje (DUARTE, 2004, p. 318-319).

Que História da Ciência atenderia a essas expectativas? ${ }^{2}$

A legislação educacional brasileira em vigor, o texto da Base Nacional Curricular em discussão, bem como os editais do PNLD, separam o joio do trigo. Explicitam "modelos" de História da Ciência adequados e inadequados ao contexto didático:

É importante, porém, que esse recurso [História da Ciência] não fique limitado à descrição de fatos ocorridos no passado ou à apresentação de biografias [...] (BRASIL, 2006, p. 86).

[...] será excluída a obra que não apresentar, em seu conjunto: [...] 6. a história da ciência muito além de nomes ou datas, explorando o contexto social, cultural, econômico e político em que ocorreu a produção científica. (BRASIL, 2017, p. 46) Não se deve caracterizar o "fazer ciência" como uma sequência rígida e linear de passos pré-estabelecidos. [...]. O caráter coletivo e comunitário da prática da Física é algo que merece ser ressaltado (BRASIL, 2015, p. 205).

Quando os conteúdos disciplinares são apresentados nos livros didáticos, a sequência das transformações pelas quais passaram acaba mascarando dificuldades, e eles são mostrados tão simplificados que parece ao aluno ser necessário apenas decorar as fórmulas e os principais conceitos, sem a necessidade de perguntar de onde vieram esses saberes. Será que Newton expressou a lei da gravitação universal tal como a conhecemos, $\mathrm{F}=\mathrm{GMm} / \mathrm{r} 2$ ? Foi essa a forma originalmente proposta por ele? (BRASIL, 2006, p. 49).

Dada sua condição [do conhecimento] de ser produto histórico-cultural, isto é, de ser produzido e elaborado pelos homens por meio da interação que travam entre si, no intuito de encontrar respostas aos mais diversificados desafios [...] o conhecimento articula-se com os mais variados interesses. [...] a produção, elaboração e disseminação do conhecimento não são neutras [...] (BRASIL, 2013, p. 180).

\footnotetext{
${ }^{2}$ Esse tipo de questionamento vem sendo recorrente: "qual tipo de história da ciência deveria ser usada?" (OLIVEIRA; SILVA, 2011, p. 1); "a qual história da ciência se deve recorrer para se atingir os objetivos educacionais" (BALDINATO; PORTO, 2008, p. 1). Não se adota nessas reflexões uma perspectiva realista de que exista a História da Ciência única, verdadeira, a ser inserida no contexto educacional.
} 
[...] o conhecimento contemporâneo guarda em si a história da sua construção. O estudo de um fenômeno, de um problema [...] está articulado com a realidade em que se insere (BRASIL, 2013, p. 183).

[...] os contextos histórico e social, e também o contexto cultural, se constituem como cenário para a construção de sentidos e significados para o conhecimento da Física e das outras ciências (BRASIL, 2006, p. 49).

Os recortes supracitados emanam o posicionamento contrário à visão de uma ciência neutra, rejeitam o empirismo indutivismo e a ideia de cientistas isolados que aplicam rigidamente um método científico único.

Há certo alinhamento entre visões historiográficas atuais e as indicações relativas à inserção didática da História da Ciência em documentos educacionais. Não há a História da Ciência única, verdadeira, a ser inserida no contexto didático. Por outro lado, certamente acarretariam efeitos contrários aos desejáveis a inclusão de uma História da Ciência do tipo anacrônica, Whig, hagiográfica, embasada na ideia de progresso positivista (VIDEIRA, 2007, p. $151-152)^{3}$.

Práticas educativas alinhadas a essas visões historiográficas podem colaborar para a propagação de visões simplistas sobre a ciência (BOAS et al., 2013). Uma História da Ciência puramente internalista pode colaborar para uma visão de ciência neutra. A História da Ciência de cunho hagiográfico colabora para uma visão de ciência individualista e elitista. E, por sua vez, a indicação de que cada descoberta ocorre de forma repentina, em data pontual, se interliga a uma visão empirista-indutivista (FORATO et al., 2011).

Em contrapartida, a nova historiografia da ciência estabelece, por exemplo, a inadequação de uma história meramente cronológica, que se limita aos nomes de pensadores e às datas de seus "grandes feitos". Antes e diante desse exemplo, explora os contextos na busca de "atores coadjuvantes" que contribuíram com as produções científicas, situando a ciência como construção humana coletiva.

Refere-se ao estudo das expressões de conhecimento sobre a natureza de modo contextualizado. Cada cultura, comunidade científica e época têm seus objetivos, formas de ver o mundo, critérios de verdade que regem sua ciência (ALFONSO-GOLDFARB, 1994; MARTINS, 2005).

Considerações sobre essa historiografia indicam:

Como e por que se aceitou certa ideia? Existiam alternativas? Como e por que essas alternativas foram abandonadas? Quando investigamos o passado, podemos tentar responder a essas questões (MARTINS, 1989a, p. 9).

\footnotetext{
${ }^{3}$ Hagiografia refere-se à História da Ciência que faz apologia às virtudes heroicas e grandes realizações dos pesquisadores. A história anacrônica, Whig, descreve os fatos do passado com base no que atualmente é aceito. A história Pedigree busca precursores da ciência. Esse discurso desatualizado remonta aos primeiros trabalhos de historiadores da ciência profissionais, característicos das décadas iniciais do século XX (KRAG, 1987; ALFONSO-GOLDFARB, 1994).
} 
As respostas aos questionamentos expressos na citação anterior não são únicas. Ademais, os próprios questionamentos podem variar: "A História de uma ciência permite uma multiplicidade de enfoques, dependendo das perguntas às quais o historiador se dirige" (DIAS, 2001, p. 226).

Não há a verdadeira História da Ciência. Destaca-se o esforço interpretativo empreendido pelos historiadores:

Certamente, há muitas (e boas) histórias da física, que diferem entre si tanto pela escolha e pelo grau de aprofundamento dos conteúdos abordados como pelos interesses, conhecimentos e concepções epistemológicas de seus autores. [...] essa história é dependente de quem a interpreta, que, longe de ser um observador neutro, tem as suas convicções teóricas sobre os assuntos abordados, o que amplia e diversifica ainda mais os caminhos. (PEDUZZI, 2011, p. 16).

\title{
História da Ciência em livros didáticos
}

Em geral, os conteúdos científicos são apresentados nos livros didáticos de forma descontextualizada, sem referência ao seu desenvolvimento histórico.

\begin{abstract}
Os livros científicos didáticos enfatizam os resultados ao qual a ciência chegou - as teorias e conceitos que aceitamos, as técnicas de análise que utilizamos - mas não costumam apresentar algum outro aspecto da ciência. De que modo as teorias e os conceitos se desenvolvem? Como os cientistas trabalham? Quais as ideias que não aceitamos hoje em dia e que eram aceitas no passado? (MARTINS, 2006, p. xxi).
\end{abstract}

A História da Ciência, quando aparece, se reduz a uma versão anacrônica, linear, narrando apenas a visão dos "vencedores", isto é, o conhecimento aceito (PEDUZZI, 2001; PAGLIARINE; SILVA, 2006; BATISTA et al., 2007). A necessidade de atenção a fundamentos historiográficos atualizados não costuma ser observada (MARTINS, 2006; BALDINATO; PORTO, 2008; OLIVEIRA; SILVA; 2011; FORATO et al., 2011; GUERRA, 2014). Esse "descuido" contraria as indicações da literatura especializada, bem como as sinalizações da legislação educacional:

[uma] história da ciência, muitas vezes restrita à história de 'fatos, anedotas e heróis', infelizmente, parece não ter sido ainda abandonada nas salas de aula de ciências, ainda que não faltem alertas na literatura (PRESTES; CALDEIRA, 2009, p. 6).

Há simplificações grosseiras na alusão aos elementos históricos e omissões com consequências perniciosas (MARTINS; BRITO, 2006; PAGLIARIN; SILVA, 2006; BATISTA et al., 2007; VIDAL; PORTO, 2012). O empirismo-indutivismo está implícito em episódios como a maçã de Newton, a banheira de Arquimedes e a descoberta da pressão atmosférica por Torricelli. As pseudo-histórias desvalorizam a percepção da criatividade e da colaboração no trabalho científico (ALLCHIN, 2003). Podem transmitir visões simplistas:

[...] os cientistas exercem um papel heroico dentro destes mitos. Essa grandiosidade com que a figura do cientista é tratada dentro de certo episódio histórico faz uma alusão àqueles personagens literários que não exibem falhas em seu caráter bem como o fato de nunca cometerem erros. Outro notável item nessas caricaturas dos 
cientistas é que descobertas científicas que ocorreram gradualmente e contaram com a colaboração do trabalho árduo de várias pessoas são creditadas pura e simplesmente a uma única pessoa. [...] essas descobertas vêm acompanhadas de uma data precisa, dando a impressão de que ocorreram num determinado dia ou ano após um único momento de introspecção dos cientistas transformando-os em superhumanos (PAGLIARINE; SILVA, 2006, p. 4).

Em geral, características negativas dessas narrativas não são percebidas pelo professor uma vez que ele próprio costuma estar imerso em visões empiristas-indutivistas (SILVEIRA, 1992; GIL-PÉREZ et al., 2001). Outro aspecto importante é o despreparo do docente para uma apreciação crítica dos pressupostos historiográficos implícitos:

Muitas vezes não percebe os problemas dessas versões, pois não é um profissional treinado em História e Filosofia da Ciência (MARTINS; BRITO, 2006, p. 246).

Na maioria das vezes os professores não se dão conta de apresentações anacrônicas. Quando perguntados sobre se determinados livros realizam uma abordagem histórica respondem positivamente, mas "a História da Ciência, a que esses professores se referem, é a história cronológica" (BRINCKMANN, 2008, p. 82). Há dificuldade quanto a perceberem $o$ que é a História da Ciência e suas possibilidades de usos na educação (MARTINS, 2006, p. xxvix).

Face às referidas dificuldades, destacamos que, mesmo sem conhecer profundamente o desenvolvimento histórico de cada conceito, é possível perceber algumas lacunas na História da Ciência apresentada em livros didáticos. Certos indícios de fragilidade são evidenciados pela ausência de respostas a questionamentos aplicáveis aos diversos conteúdos científicos:

- Que situações ou problemas fomentaram o desenvolvimento do referido conceito?

- Que concepções científicas sobre os fenômenos citados precederam o atual conhecimento sobre esses fenômenos?

- $\quad$ O referido conhecimento científico se estabeleceu a partir de uma descoberta pontual de um único personagem ou foi desenvolvido coletivamente? Como isso ocorreu? Houve controvérsias?

Utilizamos esse tipo de questionamento na análise de uma amostra de livros do Ensino Médio $^{4}$, focalizando especificamente o conteúdo de pressão atmosférica. Examinamos, ainda, esse conteúdo específico nos materiais didáticos à luz de fundamentos historiográficos atualizados. Esses pressupostos da nova historiografia da ciência se referem, por exemplo, à rejeição de histórias anacrônicas, de narrativas apologéticas a "grandes personagens" e suas descobertas repentinas e de narrativas que descrevem ideias de outras épocas parecendo fluir

\footnotetext{
${ }^{4}$ A pesquisa valeu-se de uma amostra de livros do Ensino Médio, usualmente disponíveis no mercado editorial. Não houve a pretensão de contemplar todos os livros aprovados em editais do PNLD.
} 
diretamente em direção a teorias atualmente aceitas (MARTINS, 2004; FORATO et al., 2011) ${ }^{5}$. Por fim, aprofundando a discussão, recorremos a fontes primárias e secundárias da História da Ciência relacionadas ao desenvolvimento desse conceito.

Consideramos que a análise pode contribuir produtivamente para o leitor, por não ser uma consideração geral sobre as inadequações da História da Ciência presente nos livros didáticos. Parte-se do pressuposto de que saber que os livros didáticos são historicamente descontextualizados é pouco, se comparado a saber como essa descontextualização se apresenta. O resultado foi dividido em tópicos refletindo características significativas observadas.

\section{Análise dos livros didáticos}

Centralização na figura de Torricelli

Os livros didáticos de Física usualmente trazem poucas referências à História da Ciência. Em alguns casos, textos curtos com conteúdo histórico são deslocados para apêndices (com títulos característicos como "Física tem história", "Para saber mais. Sempre foi assim?"). Esse procedimento pode desvalorizar o texto isolado, caracterizando-o como acessório.

Quando presente ao longo dos capítulos, a História da Ciência geralmente se resume a quadros ilustrativos e informações, como nomes de pesquisadores considerados mais relevantes, suas datas de nascimento, morte, nacionalidade e descobertas. No que concerne ao conteúdo pressão atmosférica, essas informações muitas vezes são centralizadas na figura de Evangelista Torricelli. Vejamos alguns exemplos:

Quem, pela primeira vez, percebeu que o ar exercia pressão e propôs uma experiência para medir a pressão atmosférica foi o físico italiano Evangelista Torricelli (1608-1647) (TORRES et al., 2010, p. 154) ${ }^{6}$.

O primeiro experimento para medir a pressão atmosférica foi elaborado por um discípulo de Galileu, o físico italiano Evangelista Torricelli (1608-1647) (OLIVEIRA et al., 2011, p. 247).

O físico italiano Torricelli (Contemporâneo e amigo de Galileu) foi a primeira pessoa a fazer uma experiência para medir o valor da pressão atmosférica (MÁXIMO; ALVARENGA, 2003, p. 94.

Isso pode ser feito repetindo-se um experimento realizado pelo matemático e físico italiano Evangelista Torricelli, em 1643 (SAMPAIO; CALÇADA, 2008, p. 198).

Informações que associam o conhecimento científico a seres humanos poderiam contribuir para uma visão de ciência como construção humana. No entanto, esses elementos

\footnotetext{
${ }^{5}$ Importante ratificar que a referência a tais inadequações não significa adotar a perspectiva de que existe "a real história da ciência" a ser confrontada com "a história fictícia dos livros didáticos". Não se assume aqui uma visão "objetivista" da realidade histórica.

${ }^{6} \mathrm{O}$ mesmo texto aparece em edição anterior da obra, de 2005.
} 
não parecem ser incluídos em livros didáticos em perspectiva formativa consistente relacionada à Natureza da Ciência. Sua mera citação não caracteriza a realização de uma abordagem histórica.

Qual a qualidade da informação trazida pelos trechos transcritos anteriormente?

Tomando como base a Historiografia da Ciência, podem ser percebidas características de uma História da Ciência Pedigree. Há centralização na busca de precursores do conhecimento científico: "Quem, pela primeira vez, percebeu", "O primeiro experimento", “foi a primeira pessoa a". A ênfase está na sinalização de que o personagem Torricelli e seu experimento representam um marco para a ideia de pressão atmosférica a ser (re) conhecido e referenciado.

Didaticamente, esse estilo contribui para o fortalecimento de visões individualistas da ciência, em contraposição a uma construção coletiva. Referências usuais suscitam a impressão de que coube a Evangelista Torricelli o protagonismo de evidenciar a influência da pressão atmosférica nos fenômenos do dia a dia. Há exemplares que afirmam isso explicitamente. Mas seria, de fato, correto afirmar que Torricelli foi quem "pela primeira vez, percebeu que o ar exercia pressão" (TORRES et al., 2010, p. 154)?

Segundo historiadores da ciência, a ideia de pressão do ar é anterior aos trabalhos de Torricelli e não pode ser centralizada em um personagem exclusivo:

No início do século XVII, algumas pessoas já pensavam sobre o peso do ar e a pressão atmosférica. Um deles foi Isaac Beeckman, um holandês, que é bem conhecido pelos seus trabalhos com Descartes (MARTINS, 1989a, p. 24; grifo nosso) .

As considerações de Isaac Beeckman (1588-1637) sobre a pressão do ar foram realizadas a partir de pilares fornecidos por outros pesquisadores. Ele tomou como base contribuições do seu professor Simon Stevin (1548-1620) à hidrostática (LONGUINI; NARDI, 2002, p. 74). Fazendo analogia entre os comportamentos do ar e da água, Beeckman explicou:

\footnotetext{
Mostrei que o ar é pesado, que ele nos pressiona de todos os lados de um modo uniforme, de modo que não sofremos por essa pressão e que essa gravidade é a causa daquilo que se chama horror ao vazio[...]. [...] as coisas se precipitam com grande poder para um lugar vazio, por causa da grande altura do ar que está acima delas e pelo que daí resulta (BEECKMAN, Mathematico-physicarum meditationem apud MARTINS, 1989a, p. 25).
}

O período da Revolução Científica deu início ao uso da ideia de pressão do ar em explicações para o funcionamento de ventosas, sifões, canudos para sorver líquidos e bombas de água. Essa nova perspectiva foi expressa inclusive por Torricelli: “Tentei, portanto, com esse princípio [pressão atmosférica], explicar todo tipo de repugnância sentida nos vários 
efeitos atribuídos ao vácuo, não tendo, até agora, encontrado nada que não dê certo" (TORRICELLI, Carta a Michelangelo Ricci apud MAGIE, 1969, p. 71) ${ }^{7}$.

Um dos livros didáticos analisados traz um comentário equivocado, que ignora a existência de explicações para esse tipo de fenômeno anteriormente a Torricelli:

Ao bombear água de poços através de bombas aspirantes, verifica-se que ela sobe dentro do tubo até uma altura de aproximadamente $10,3 \mathrm{~m}$, e não mais que isso. Durante muito tempo esse fato ficou sem explicação. No século XVII, Torricelli resolveu o problema através da seguinte experiência [...]. (PARANÁ, 1999, p. 402403; grifo nosso)

Ao contrário do que esse exemplar afirma, em geral, considerava-se que, nas bombas, a água subia porque a natureza evitava a formação do vazio. Alternativamente, na época, sugeriu-se que as bombas sugavam o ar dos canos, reduzindo aí a pressão; a atmosfera pressionava a água fora do cano e esta era forçada a subir pelo mesmo. Alguns estudiosos sustentavam outras explicações, tais como, a existência de uma espécie de "puxão" exercido pelo vazio. Houve, portanto, uma pluralidade de ideias.

Na década de 1630, o pesquisador Giovanni Baliani (1582-1666), recorreu a Galileu Galilei (1564-1642) em busca de solução para o não funcionamento de um sifão (MARTINS, 1989a, p. 27). A intenção era fazer a água passar de um vale a outro, por meio de um sifão que precisava subir uma colina de pouco mais de 20 metros. Os dois lados do sifão foram preenchidos com água e tampados na parte inferior. Quando destampados, a água saiu completamente pelos dois lados. O sifão não funcionou.

Galileu tinha uma explicação para a ineficiência. A "força do vácuo" era suficiente para elevar uma coluna de água com uma bomba até no máximo pouco mais de dez metros. A altura máxima era inversamente proporcional ao peso específico do líquido, que se comportava como uma corda ao ser erguida:

E, de fato, a coisa que é atraída pela bomba não é uma coluna de água presa na parte superior e esticada mais e mais até que finalmente atinge-se um ponto no qual ela quebra como uma corda, por conta do seu peso excessivo? (GALILEU, Duas Novas Ciências apud MAGIE, 1969, p. 69).

No contexto dessa discussão, Baliani realizou considerações sobre o peso do ar e a possibilidade de formar um espaço vazio:

\footnotetext{
${ }^{7}$ Livros didáticos costumam mencionar a subida do líquido no canudo, mas apenas a explicação atual é apresentada: "A pressão atmosférica atua na superfície do líquido, fazendo-o subir" (MÁXIMO; ALVARENGA, 2011, p. 241); “[...] devemos sugar o ar que existe no canudo. Feito isso, a ação da pressão atmosférica sobre a superfície líquida atua empurrando o líquido" (SANT'ANNA et al., 2010, p. 321; esse trecho se assemelha ao contido na edição de 2013 da mesma obra); "Então, você não chupa o refresco, como muitas pessoas pensam. É a pressão atmosférica que o empurra para sua boca" (MÁXIMO; ALVARENGA, 2003, p. 93); "O que fazemos é aumentar levemente o volume de nosso tórax [...] a pressão atmosférica torna-se maior que a pressão do ar dentro dos pulmões e o líquido é empurrado para cima no canudinho" (SAMPAIO; CALÇADA, 2008, p. 199). O exemplar mais antigo analisado nessa pesquisa traz, além do canudo, o funcionamento de uma seringa como “Aplicações da experiência de Torricelli” (PARANÁ, 1999, p. 403).
} 
[...] estamos no fundo de sua imensidão [do ar] e não sentimos nem seu peso nem sua compressão que há por todos os lados [...]. Esse peso é muito grande, mas não infinito - e, portanto, determinado. Com força proporcional a ele, seria possível superá-lo e assim causar o vácuo. (BALIANI apud MARTINS, 1989a, p. 28)

As contribuições de Beeckman, Baliani e diversos outros personagens ao desenvolvimento do conceito de pressão atmosférica não costumam ser citadas em livros de Física. Centralizando as informações históricas na figura de um único pesquisador, afirma-se que: "Torricelli ainda obteve a primeira maneira de produzir o vácuo no interior de um tubo" (GONÇALVES FILHO; TOSCANO, 2013, p. 136).

Observa-se um roteiro comum. O conteúdo científico é apresentado, sem indicações de problemas que lhe deram origem. Mesmo em exemplares que se inclinam a uma abordagem histórica, como a coleção Física em contextos: pessoal, social e histórico, é marcante a centralização na figura de Torricelli e a descrição descontextualizada do seu experimento famoso. Antecedentes e as motivações não são citados (OLIVEIRA et al., 2011).

Esse aspecto é relevante, uma vez que o referido material privilegia a abordagem histórica para boa parte dos conteúdos, mas não o faz nesse caso. São, assim, inadequadas as orientações ao professor de que o capítulo 8 contribui para que o estudante possa “compreender a construção do conhecimento físico como um processo histórico, em estreita relação com as condições sociais, políticas e econômicas de uma época" (OLIVEIRA et al., 2011, p. 68).

Em livros didáticos, há escassas alusões ao contexto científico no qual o conceito de pressão atmosférica foi forjado. No exemplar Física para o Ensino Médio há referências contextuais. No entanto, o problema da elevação da água a uma altura superior a $10 \mathrm{~m}$ é associado a Torricelli, e não a uma construção coletiva. O debate entre Baliani e Galileu não é mencionado (YAMAMOTO; FUKE, 2013) ${ }^{8}$.

Outro exemplar analisado, e que foge à regra de omissão ao contexto, também não cita a discussão entre Baliani e Galileu. Refere-se apenas à hipótese aceita por esse último e de forma bastante nebulosa:

Galileu Galilei, em 1638, no livro 'Duas novas ciências', apresentou a ideia de um limite para a compreensão da existência o vácuo. Em sua hipótese, esse limite estaria relacionado à altura máxima atingida por uma coluna de água. Galileu parece ter-se interessado pelo assunto depois de um jardineiro ter dito a ele ser impossível elevar uma coluna de água acima de uma altura de 18 braças (aproximadamente 10 m). Galileu observou que, de fato, não era possível [...] (SANT’ANNA et al. , 2013, p. 211- 212; grifo nosso) ${ }^{9}$.

A referência à proposta de Galileu como "um limite para a compreensão da existência o vácuo" é obscura. Mesmo explicações presentes em trabalhos acadêmicos de historiadores

\footnotetext{
${ }^{8}$ Os comentários citados nessa análise se aplicam também à edição de 2010 da mesma obra.

${ }^{9}$ Os comentários citados nessa análise se aplicam também à edição de 2010 da mesma obra.
} 
da ciência são mais acessíveis: "Galileu admitia a existência de uma certa resistência à formação do vácuo; mas supunha que essa resistência era finita, mensurável; e que, portanto, o vazio podia ser formado por uma força finita” (MARTINS, 1989a, p. 32). Também trabalhos acadêmicos caracterizados como subsídios para o ensino de Física trazem referências mais adequadas ao episódio histórico (LONGUINI; NARDI, 2002).

Nas seções seguintes analisaremos mais detalhadamente, do ponto de vista histórico, outras informações encontradas ${ }^{10}$.

\section{O tubo vazio}

Nos livros didáticos, referências ao experimento de Torricelli costumam ser descontextualizadas e distorcidas. Analisemos alguns recortes:

[...] verificou que a coluna de mercúrio atingia a altura de $76 \mathrm{~cm}$, restando o vazio acima do mercúrio, região essa denominada câmara barométrica (FERRARO; SOARES, 2009, p. 428) ${ }^{11}$.

A parte superior ficou vazia, isto é, criou-se ali um vácuo. Na realidade, esse vazio não é perfeito, pois um pouco de mercúrio evaporava, preenchendo o espaço. Mas a pressão desse vapor é tão pequena que podemos admitir que nessa região há um vazio "aproximado", sendo a pressão ali quase nula $(\mathrm{Px}=0)$ (SAMPAIO; CALÇADA, 2008, p. 198).

As passagens citadas sugerem que na época de Torricelli era trivial a afirmação de que a parte superior do tubo estava vazia ou, ainda, que havia um vazio "aproximado". Registra-se o espaço vazio no alto do tubo como se este fosse evidente e incontestável.

Historicamente, o experimento de Torricelli estava relacionado ao contexto de argumentação contrária à tradição do horror ao vazio. A controvérsia sobre a existência do vazio percorreu a História da Ciência (GRANT, 1981; MARTINS, 1989a; LONGUINI; NARDI, 2002).

$\mathrm{Na}$ Antiguidade, Aristóteles e os filósofos eleatas se manifestaram contrariamente à existência do vazio. Os atomistas, por outro lado, sustentavam que o vazio existia. Para os eleatas, o vazio só precisaria existir se os movimentos existissem. No entanto, consideravam o movimento como uma percepção sensorial ilusória. Os atomistas, contrariamente, consideravam que um objeto em movimento de fato estava em movimento. E o vazio seria necessário para isso.

\footnotetext{
${ }^{10}$ Do ponto de vista historiográfico outros pontos poderiam ser mencionados sobre os trechos transcritos nessa seção. De forma anacrônica, os pesquisadores são ditos "italianos" em época na qual a Itália não existia como país, isto é, não era unificada. De forma análoga, é inadequado escrever: "O físico alemão Otto von Guericke foi um árduo defensor da existência do vácuo" (YAMAMOTO; FUKE, 2013, p. 304; grifo nosso). Apontar esses casos de anacronismo não se reduz a um mero preciosismo histórico. Salvo melhor juízo, considera-se aqui o relacionamento coerente entre as disciplinas escolares. O estudante do Ensino Médio estuda os processos de unificação da Itália e da Alemanha ocorridos no século XIX.

11 Em imagem apresentada na edição de 2012 de obra dos mesmos autores, registra-se o termo "vazio Torricelliano" em referência ao alto do tubo invertido (FERRARO et al., 2012, p. 243).
} 
O plenismo era um alicerce fundamental na física aristotélica. Aristóteles argumentou intensamente a favor de uma visão de mundo pleno, sem espaços vazios, em contexto de refutação aos atomistas. Definiu espaço de forma intrinsecamente relacionada à matéria, sendo, portanto, inconcebível um "espaço vazio". Examinou argumentos atomistas, segundo os quais a existência do vazio era necessária para que houvesse movimento, compressão, propagação da luz e outros fenômenos. Defendeu que todos esses fenômenos podiam ser explicados sem a existência do vazio. Por exemplo, usando o chamado "argumento da troca mútua”, Aristóteles sugeriu que os corpos cediam lugar um ao outro.

As considerações sobre a temática do vazio não permaneceram estáticas após Aristóteles, ainda que a posição do filósofo fosse muito influente. No século I d. C., Heron de Alexandria apoiou com argumentos empíricos a existência de vazios na matéria. Por outro lado, defendeu a "impossibilidade de um vácuo contínuo" (HERON, Pneumatica apud MARTINS, 1989a, p. 17).

As discussões medievais evidenciaram a influência aristotélica em predominante (mas não unânime) negação do vazio. O árabe Avicena e o francês Jean Buridan retomaram elementos do cotidiano (como sifões e canudos para sorver líquidos), bem como articularam experimentos imaginários, reforçando com exemplos "o horror ao vazio".

Os pensadores que admitiam a existência do vazio não eram muitos. $O$ francês Nicholas de Autrecourt foi um deles. Argumentou que quando um corpo se movia o ar a sua frente se condensava nos espaços vazios internos à matéria "ar". Ainda no período medieval, vários pesquisadores se envolveram na discussão. Marsilius de Inghen sugeriu um experimento imaginário importante. Colocando certo volume de água intensamente fria num recipiente internamente côncavo, totalmente fechado e completado com ar, a condensação dessa porção de ar supostamente deveria levar à formação de espaços vazios no interior do recipiente. No entanto, segundo Marsilius, a natureza não permitiria o vazio. A condensação ocorreria somente se o recipiente se quebrasse, permitindo a entrada do ar.

$\mathrm{O}$ experimento chamou a atenção de dissidentes. Telesio e Patrizi pensaram em uma nova versão. O recipiente côncavo, fechado, estaria totalmente cheio de água. Imaginaram que a água, ao se congelar, iria se contrair, ocupando um espaço menor (era o que se considerava na época). Ficaria, então, um espaço vazio dentro do recipiente. Nem todos concordaram. Francisco de Toledo argumentou que o espaço livre não ficaria vazio e sim cheio de "vapores sutis". Outros disseram que, para evitar a formação do vazio, o recipiente se quebraria. E outros, ainda, disseram que, para evitar o vazio, a água nem se congelaria.

O chamado "horror ao vazio" chegou à Revolução Científica como uma tradição marcante, calçada fortemente em argumentos empíricos. Esse contexto parece ser irrelevante ou mesmo desconhecido para os autores dos livros didáticos. Não costuma haver menção à 
controvérsia sobre a existência do vazio. Os poucos exemplares que escapam a essa regra, trazem referências distorcidas:

\begin{abstract}
Por mais de vinte séculos, acreditou-se que a natureza teria horror ao vácuo. No século IV a.C., Aristóteles afirmou que a existência do vazio seria impossível e, ao longo da Idade Média, essa ideia transformou-se em dogma, verdade inquestionável. Nesse período da história da humanidade, a menção a existência do vazio era considerada um grave erro. Galileu Galilei, em 1638, no livro Duas novas ciências, apresentou a ideia de um limite para a compreensão da existência o vácuo (SANT'ANNA et al., 2013, p. 211- 212; grifo nosso).
\end{abstract}

O trecho anterior faz parte de um texto de cerca de uma página, intitulado "A natureza e o suposto horror ao vácuo", colocado na forma de box. Transmite a impressão equivocada de que Aristóteles fez uma mera afirmação, sem fundamentá-la, fora de um contexto de debate. Erroneamente, indica a ausência de questionamentos ao horror ao vazio no período antecedente à Revolução Científica. Conduz a uma atribuição de valor inferior às posições do passado "dogmático" frente ao que seria defendido no século XVII.

Os antecedentes e o contexto científico

Nos materiais didáticos, os antecedentes ao experimento de Torricelli costumam ser ausentes ou distorcidos. Ao longo do século XVII, as discussões sobre o vazio continuaram. A defesa do vazio ganhou evidência com a retomada de argumentos atomistas. Novos rumos surgiram em meio à visão de que o ar exercia pressão. O experimento de Gasparo Berti (1600-1643), praticamente ausente nos livros didáticos, foi realizado em 1641, sendo um antecedente importante para o trabalho de Torricelli (MARTINS, 1989a; LONGUINI; NARDI, 2002).

No exemplar de material didático que contém o texto "A natureza e o suposto horror ao vácuo", o experimento de Berti não é citado. Indica-se que “Torricelli substituiu a água por argento-vivo (mercúrio)” (SANT’ANNA et al., 2010, p. 320). Contudo, não há explicação sobre o contexto dessa "substituição". Parece que, de repente, com a intenção de medir a pressão atmosférica, Torricelli fez aquela montagem bastante específica, inclusive usando mercúrio em vez de água ${ }^{12}$, embora essa certamente fosse mais acessível. Ignora-se a montagem que inspirou Torricelli.

Berti utilizou um longo tubo de chumbo, que do solo alcançou o segundo andar de uma edificação. $\mathrm{O}$ tubo totalmente preenchido com água estava apoiado verticalmente em um tonel de água. Quando a torneira da base do tubo foi aberta, parte da água fluiu para o tonel.

\footnotetext{
${ }^{12}$ Alguns exemplares comentam sobre a possibilidade de realizar com água o experimento de Torricelli, mas não citam que isso foi de fato realizado e o antecedeu: "Se a experiência de Torricelli for realizada com água (ao nível do mar), a altura da coluna líquida será de 10,3m" (MÁXIMO; ALVARENGA, 2011, p. 240); "Caso reproduzíssemos o experimento utilizando água em vez de mercúrio, a coluna no tubo teria altura 13,6 vezes maior [...]" (SANT'ANNA et al., 2010, p. 324); "Se o mercúrio usado na experiência de Torricelli for substituído por água [...]” (KANTOR et al., 2010, p. 238).
} 
Uma coluna de água permaneceu no tubo. Historicamente, o experimento de Berti priorizou a discussão do eventual conteúdo da região superior do tubo: estaria este vazio? (MARTINS, 1989a, p. 35).

Não era possível visualizar o conteúdo do longo tubo, cuja produção em vidro era então inviável. A substituição da água pelo mercúrio possibilitou o uso de um tubo de vidro de cerca de um metro. A montagem tornou-se portátil e o conteúdo visível.

Historicamente, há suspeitas de que Vincenzo Viviani (1622-1703) teria realizado o experimento com mercúrio antes de Torricelli. Ambos eram seguidores de Galileu Galilei, para quem, como mencionamos, a altura máxima atingida era inversamente proporcional ao peso específico do líquido. Não se sabe de quem teria sido a ideia da troca do líquido: "É possível que a própria ideia de utilizar mercúrio, ao invés de água, tivesse sido de Viviani ou de Galileu" (MARTINS, 1989a, p. 36).

Sobre Viviani há raras indicações em materiais didáticos:

[...] Vincenzo Viviani (1622-1703), físico e matemático italiano, encheu boa parte de um tubo de cerca de $1 \mathrm{~m}$ com mercúrio líquido $(\mathrm{Hg})$, tampou-o e em seguida colocou-o invertido dentro de uma cuba também contendo mercúrio. Após destampar o tubo, o nível do mercúrio dentro do tubo desceu e estabilizou-se a uma altura de $76 \mathrm{~cm}[\ldots]$. Torricelli e Viviane notaram também que a altura da coluna de mercúrio que se mantinha no tubo dependia da altitude em que a experiência fosse realizada (YAMAMOTO; FUKE, 2013, p. 299).

A passagem anterior foi extraída de um texto de conteúdo histórico disposto em apêndice no livro Física para o Ensino Médio. As informações históricas, notadamente em tom de certeza, podem transmitir a impressão de um trabalho conjunto de Viviani e Torricelli, contrastando com o tom hipotético manifestado por historiadores da ciência.

Ainda sobre a contextualização, há outro aspecto relevante. Os objetivos da montagem de Berti, que serviram de inspiração a Torricelli, se enquadravam na controvérsia sobre o vazio. O próprio Torricelli inseria explicitamente o experimento com o mercúrio na mesma ambiência.

Em carta de 1644 ao pesquisador Michelangelo Ricci, ao descrever o seu experimento, Evangelista Torricelli indicou que não havia consenso na época sobre a existência do vazio. Suas motivações decorrentes do engajamento na controvérsia vieram à tona.

Muitos disseram que o vazio não existe, outros que de fato existe apesar da repugnância da natureza e com dificuldade; eu não conheço alguém que tenha dito que exista sem dificuldade e sem uma resistência da natureza. Aceito a existência do vácuo, mas ele ocorre com alguma resistência na natureza (TORRICELLI, Carta a Ricci apud MAGIE, 1969, p.71).

Na carta, Torricelli se empenhou em sustentar argumentação baseada em evidências empíricas a respeito da porção superior do tubo. Indicou, entre outros argumentos, que a parte superior do tubo, abandonada pelo mercúrio, podia ser novamente preenchida, o que seria 
indicativo de estar vazia. A não trivialidade da assertiva de Torricelli contrasta com a descrição presente em livros didáticos.

Os livros de Física deixam a impressão de que o experimento de Torricelli "brotou" do nada. Torricelli foi "iluminado", responsável por descobrir sozinho o que sabemos hoje. Em contraste com essa impressão, historicamente o experimento esteve relacionado a uma controvérsia coletiva de construção de conhecimento.

Não pode ser caracterizado como uma simples medida da pressão atmosférica, ao contrário do que afirmam alguns exemplares: "A experiência de Torricelli (físico e matemático italiano) consiste na determinação da pressão atmosférica num determinado local” (KANTOR et al., 2010, p. 238). Diferentemente disso, nas palavras do próprio Torricelli:

\begin{abstract}
Não fui capaz de concretizar minha intenção principal, isto é, reconhecer quando a atmosfera é mais densa e mais pesada e quando é mais sutil e mais leve, porque o nível $\mathrm{AB}$ no instrumento $\mathrm{EC}$ varia por alguma outra razão (o que eu não teria acreditado) especialmente como se fosse sensível ao frio ou ao calor, exatamente como se o tubo AE estivesse cheio de ar (TORRICELLI, Carta a Ricci apud MAGIE, 1969, p. 72).
\end{abstract}

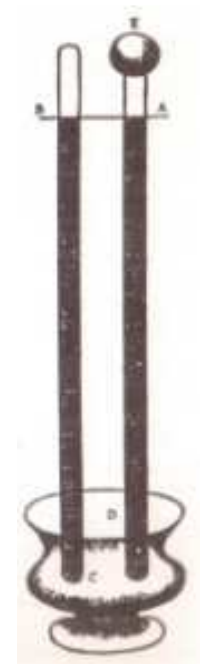

Figura 01 - Desenho contido na carta de Torricelli

Fonte: Carta transcrita em MAGIE, 1969, p. 72.

Nota-se, assim, que Torricelli não demonstrou sucesso imediato quanto à medida da pressão atmosférica, muito embora seja essa a impressão causada pelos livros didáticos:

[...] afirmou que a medida da pressão atmosférica, ao nível do mar, equivalia a 76 $\mathrm{cm}$ de mercúrio. [...] percebeu que a altura do mercúrio no tubo podia variar ligeiramente de um dia para o outro, o que evidenciava pequenas mudanças na própria pressão atmosférica. [...] (GONÇALVES FILHO; TOSCANO, 2013, p. 136).

Os escritos originais de Torricelli retratam, ao contrário do que costuma aparecer em materiais didáticos (BONJORNO et al, 2013; DOCA et al., 2010; FERRARO; SOARES, 2003; GASPAR, 2011), que o próprio pensador não finalizou categoricamente suas conclusões sobre o experimento. 


\section{O empirismo-indutivismo permeando a descrição}

Durante muito tempo esse fato [funcionamento das bombas aspirantes] ficou sem explicação. No século XVII, Torricelli resolveu o problema através da seguinte experiência [...] (PARANÁ, 1999, p. 402-403).

Ao destampar o tubo, Torricelli verificou que a coluna liquida desceu, estacionando a uma altura de $76 \mathrm{~cm}$ acima do nível do mercúrio no recipiente [...]. Concluiu, então, que a pressão atmosférica, [...], atuando na superfície do líquido no recipiente, equilibrava a coluna de mercúrio. Portanto, o valor da pressão atmosférica equivale à pressão exercida por uma coluna de mercúrio de $76 \mathrm{~cm}$ de altura (MÁXIMO, ALVARENGA, 2003, p. 94).

O físico italiano Evangelista Torricelli (1608-1647), contemporâneo e amigo de Galileu, realizou uma famosa experiência que, além de demonstrar que a pressão atmosférica existe realmente, permitiu a determinação do seu valor. [...]. Torricelli verificou que a coluna líquida descia, até estacionar a uma altura de cerca de $76 \mathrm{~cm}$ acima do nível do mercúrio no recipiente. Concluiu, então, que a pressão atmosférica, pa, atuando na superfície do líquido no recipiente, conseguia equilibrar a coluna de mercúrio. Observe que, acima do mercúrio, no tubo, temos vazio [...] (MÁXIMO; ALVARENGA, 2011, p. 239).

[...] concluiu corretamente que essa coluna de mercúrio era equilibrada pela pressão atmosférica exercida na superfície livre da cuba, ao nível do mar, onde realizou o experimento. (GASPAR, 2011, p. 333).

Verificou que, no local em que fez o experimento, a coluna de mercúrio desceu até se manter a $76 \mathrm{~cm}$ do nível de mercúrio no recipiente. Concluiu, daí, que a pressão exercida pelo ar, isto é, a pressão atmosférica no ponto A (p_A), equivalia à pressão exercida no ponto B (p_B) por uma coluna de mercúrio com $76 \mathrm{~cm}$ de altura (TORRES et al., 2010, p. 154).

Torricelli concluiu da experiência que a pressão do ar sobre a superfície livre do mercúrio no recipiente era igual a pressão dos $76 \mathrm{~cm}$ de mercúrio contidos no tubo (FERRARO; SOARES; 2009, p. 428).

Torricelli mediu a altura da coluna de mercúrio no tubo e encontrou $76 \mathrm{~cm}$. Considerou, então, tal valor como a medida da pressão atmosférica ao nível do mar (SANT'ANNA et al, 2010, p. 318).

Em geral, as referências em livros didáticos não indicam que houve interpretações divergentes para o fenômeno da sustentação do mercúrio. Transparece a uniformidade de ideias. Parece que as conclusões "tiradas" do experimento foram simplesmente aceitas.

Poderia ser diferente, isto é, havia possibilidade de contradizê-las? O leitor das passagens citadas anteriormente pode ter a impressão de que não.

Os trechos parecem sugerir que era de fato observado que a sustentação do mercúrio se devia a algo externo, a pressão atmosférica. $\mathrm{O}$ experimento seria a fonte do conhecimento, mostrando esse resultado.

Torricelli percebeu que o mercúrio não descia completamente e que havia um vazio na parte superior do tubo. A pressão atmosférica atuava sobre o metal liquido (STEFANOVITS, 2013). Mediu a pressão atmosférica, causa inequívoca da sustentação do mercúrio: “Outra 
consequência importante desse experimento é a descoberta de que o ar tem um peso cujo valor pode ser determinado" (GONÇALVES FILHO; TOSCANO, 2013, p. 136). Para isso, “idealizou [sem antecedentes?] um experimento muito simples e engenhoso" (GONÇALVES FILHO; TOSCANO, 2013, p. 135). O “experimento de Torricelli” é uma medida da pressão atmosférica (FERRARO et al., 2012; STEFANOVITS, 2013).

Seriam essas indicações adequadas do ponto de vista histórico?

Trata-se de uma História com características Whig, que dá exclusiva relevância às ideias "vencedoras". Há uma substituição ou distorção das motivações, escolhas, problemas e objetivos originais de Torricelli, que respondem a arcabouços científicos do passado, por uma descrição de resultados pasteurizada, anacrônica, enquadrada à visão científica prevalecente. No chamado whiguismo, o passado é julgado de acordo com parâmetros posteriores. Torricelli “concluiu corretamente” (GASPAR, 2011, p. 333).

Privilegia-se o ensino do produto da ciência já pronto, sem o processo controverso que lhe deu origem. Há uma pseudo-história - narrativa equivocada construída a partir da deturpação de fatos - que gera uma imagem simplista acerca da ciência (ALLCHIN, 2003). Não transparecem hesitações, questionamentos. Marcados por uma postura empiristaindutivista, os livros ingenuamente sugerem que o experimento mostra (por si próprio) a atuação da pressão atmosférica de forma inequívoca, sem que haja espaço para outras explicações.

Poucos exemplares destacam a participação do pesquisador no experimento, permitindo vislumbrar traços mais complexos da Natureza da Ciência: "Torricelli interpretou esse resultado afirmando que o que mantinha a coluna nessa altura era a pressão atmosférica" (SAMPAIO; CALÇADA, 2008, p. 198; grifo nosso). Embora não cite outras possibilidades de interpretação, a narrativa contida no recorte anterior tangencia a postura mantida por Torricelli ao expressar sua opinião sobre a causa da sustentação da coluna de mercúrio:

\begin{abstract}
Costuma ser dito como explicação para o fato de que o tubo AE permanece vazio e o mercúrio, embora pesado, seja sustentado no tubo AC, que, como se acredita até agora, a força que impede que o mercúrio caia, como naturalmente o faria, é interna ao tubo $\mathrm{AE}$, e provém do vazio ou de alguma substância extremamente rarefeita; mas afirmo que é externa, e que essa força vem de fora. Sobre a superfície do líquido que está na bacia repousa o peso de uma [coluna de] altura de cinquenta milhas de ar; então, e se no tubo $\mathrm{CE}$, no qual o mercúrio não sofre tendência ou repugnância alguma, nem mesmo mínimas, a estar lá, devesse entrar e subir uma coluna alta o suficiente para entrar em equilíbrio com o peso do ar exterior que o força a subir? (TORRICELLI, Carta a Ricci apud MAGIE, 1969, p. 72).
\end{abstract}

Torricelli deixou claro que existiam na época diferentes opiniões em relação à causa da sustentação do mercúrio. Era partidário de uma compreensão dissidente ("mas afirmo que") - a causa era externa, o mercúrio era empurrado pelo ar - enquanto que a visão mais 
tradicional ("Costuma ser dito", "como se acredita até agora") se relacionava ao horror ao vazio, uma causa interna.

Experimento crucial?

Poucos exemplares fazem referência ao horror ao vácuo, contextualizando o experimento de Torricelli. No entanto, mesmo nesses casos há distorções.

O livro Física para o Ensino Médio apresenta o box “A Física na História: A pressão atmosférica e a invenção do barômetro". O texto traz o experimento de Torricelli como um "experimento crucial”, responsável por "derrubar" o horror ao vácuo:

Com a realização desse experimento, Torricelli e Viviane comprovaram que o ar tem peso, inventaram o barômetro (medidor da pressão atmosférica) e fizeram cair por terra a afirmação de Aristóteles de que a natureza "tem horror ao vácuo"- a tal "horror" nos referiremos mais adiante (YAMAMOTO; FUKE, 2013, p. 299) ${ }^{13}$.

No mesmo capítulo, o esclarecimento posterior sobre o "horror ao vácuo" resume-se à afirmação: "Acreditava-se que a natureza preenchia imediatamente, sem medir esforços, todos os espaços vazios que não contivessem matéria" (YAMAMOTO; FUKE, 2013, p.304). Essa afirmação está contida em outro box Física na História, intitulado "A experiência dos Hemisférios de Magdeburg”. O texto comenta sobre a experiência de Magdeburg como argumento empírico favorável à existência do vácuo ${ }^{14}$, contradizendo a passagem anterior, que havia citado o experimento de Torricelli como encerramento da controvérsia. Assim, a hipótese anteriormente dita "derrubada" pelo experimento de Torricelli "ainda prevalecia":

Em sua época [de von Guericke] a ideia de Aristóteles de que a natureza tem 'horror ao vácuo' ainda prevalecia (YAMAMOTO; FUKE, 2013, p. 304).

As expressões "acreditava-se" e "ainda" tendem a desqualificar o "horror ao vácuo", indicando que o mesmo deveria ter sido abandonado face aos inequívocos resultados experimentais.

\footnotetext{
${ }^{13}$ No manual do professor (YAMAMOTO; FUKE, 2013, p. 445-446) há o seguinte destaque: "Atividade sugerida: o experimento de Torricelli". O objetivo da atividade seria fazer "uso de experimentos para auxiliar na compreensão do problema enfrentado por Torricelli, que originou o barômetro. Para isso, os experimentos visam auxiliar na relação entre a diferença de pressão e altura da coluna do líquido e mostrar de que modo a densidade também influencia essa altura". No item preparação e aplicação sugere-se a leitura do texto "A Física na História" para discutir com os alunos "sobre o que eles entenderam da leitura" e "estabelecer o paralelo entre a altura da coluna de mercúrio e água e as respectivas densidades". As indicações aos professores são vagas, não direcionando para a construção do conhecimento. O texto histórico, em si, é pouco claro, possivelmente mesmo para o professor. Não há indicação de fontes consultadas. Os experimentos propostos seriam, por exemplo: 1) tomar suco com canudo maior ou menor, notando qual seria mais fácil; 2) assoprar o canudo em lata contendo água e depois álcool. As indicações ao professor não colaboram para uma problematização. Pelo contrário, sintetizam respostas únicas: "Foi mais difícil assoprar com água ou com álcool? Justifique. Resposta possível: com a água, porque ela possui densidade maior".

${ }^{14}$ Poucos exemplares citam a experiência de Magdeburg: a separação de hemisférios de uma esfera oca necessitou de 16 cavalos (SANT'ANNA et al., 2010, p. 312; MÁXIMO; ALVARENGA, 2003, p. 93; MÁXIMO; ALVARENGA, 2011, p. 241). Não costumam indicar seu papel na discussão sobre o vazio.
} 
Historicamente, sabe-se que a discussão sobre o vazio prosseguiu, de modo que o experimento de Torricelli não derrubou o "horror ao vazio". Posteriormente, Blaise Pascal (1623-1662) referiu-se a essa hipótese tradicional, descrevendo novos experimentos. Retomou os argumentos de Torricelli:

As opiniões estavam divididas, uns estavam satisfeitos por dizer que ela [a natureza] simplesmente o evita, os outros sustentavam que ela não o podia sofrer [o vazio], eu trabalhei no meu resumo do tratado do Vácuo para destruir aquela última opinião, e creio que as experiências que eu relatei são suficientes [...] (PASCAL, 1648, p. 3).

Apesar da pretensão de Pascal, sua troca de correspondência com o Padre Noël demonstra a continuidade da controvérsia (MARTINS, 1989b). Para Noël, uma matéria sutil preenchia o espaço aparentemente vazio nos tubos. Nöel havia sido professor de René Descartes, para quem a impossibilidade do vazio decorria de sua própria definição de espaço intrinsecamente relacionado à matéria.

As referências a Blaise Pascal em livros didáticos costumam ser raras e isoladas de debates. Em geral, trazem apenas o enunciado pronto do Princípio de Pascal. Raramente apontam relação entre os trabalhos de Pascal e de Torricelli.

Historicamente, no entanto, sabe-se que Florin Périer, cunhado de Pascal, realizou o experimento de Torricelli em diferentes altitudes, ao longo da montanha Puy-de-Dôme, na França. A realização do experimento havia sido solicitada por Pascal, então partidário da interpretação de Torricelli e atento à controvérsia persistente na época. Tomando como ponto de partida que a pressão diminuía com a altitude, Pascal supunha que a coluna de mercúrio seria menor à medida que subissem a montanha. Caso o "puxão do vazio", não a pressão do ar, fosse responsável pela sustentação da coluna, essa não deveria variar em tamanho. Pascal reagiu de forma entusiasmada ao relato de Périer sobre o decréscimo da coluna de mercúrio (PASCAL, 1648).

Os livros didáticos não costumam trazer o experimento do Puy-de-Dôme. Há algumas indicações, de cunho notadamente simplista de que Blaise Pascal "repetiu a experiência no alto de uma montanha e verificou que o valor de pa era menor do que ao nível do mar" (MÁXIMO; ALVARENGA, 2011, p. 239) ${ }^{15}$. Ao contrário do que esse exemplar expressa, no entanto, a diminuição da pressão com a altitude foi ponto de partida para Pascal e não um aspecto "verificado". A intenção de Pascal não era medir a pressão atmosférica ao longo da subida, mas sim oferecer respostas sobre a causa da sustentação da coluna de mercúrio.

Assim, pode-se notar que a História da Ciência é bem mais rica e potencialmente interessante do ponto de vista didático do que os livros sugerem. Para seu uso em sala de aula, a consulta a trabalhos especializados é imprescindível.

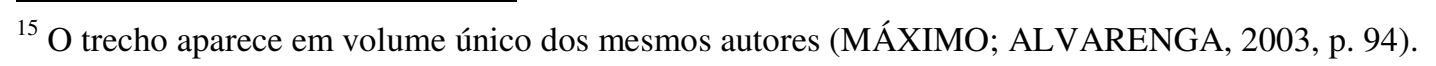




\section{Considerações finais}

A presente pesquisa foi direcionada para a abordagem histórica do conceito de pressão atmosférica, focalizando especialmente o experimento de Torricelli. Anacronismo, pseudohistória, ausência de explicações sustentadas por pensadores do passado e uma abordagem descontextualizada do experimento foram observados. Notou-se que o conceito de pressão atmosférica é geralmente enunciado de forma pronta. Há breves referências históricas que não fazem jus ao desenvolvimento histórico. Essas distorções e equívocos trazem implicações significativas para a área da educação em ciências. Os exemplares analisados não cumprem o papel didático que caberia à História da Ciência de acordo com a legislação educacional, os editais do PNLD e as indicações acadêmicas especializadas.

Não seria adequado generalizar esses resultados para todos os livros didáticos ou, ainda, afirmar que a transposição didática da História da Ciência é trivial. Trata-se de uma tarefa hercúlea: realizar recortes significativos da História da Ciência, apropriados a contextos e objetivos educacionais específicos, inserindo-os em propostas articuladas aos conteúdos científicos. Esse processo demanda atenção a considerações expressas na legislação educacional e deve refletir critérios mínimos de qualidade em termos historiográficos.

Manter o atual panorama nas publicações dirigidas à sala de aula é praticar uma visão de ciência aproblemática, deixando o aluno com a impressão de que do nada os cientistas gênios tiveram a ideia de produzir um novo conceito. Por outro lado, a História da Ciência, e, particularmente, os episódios históricos que circundam o (já onipresente) experimento de Torricelli, poderiam levar o aluno a pensar e refletir:

[...] procurar se inteirar de como se pensava em cada época, deixar de lado, temporariamente, nossas certezas, penetrando na real efervescência histórica. Essa história nos ensinará mais sobre o vazio e a pressão atmosférica, mais sobre a história do pensamento humano, mais sobre o caminho seguido pelos pesquisadores, sobre suas tentativas, hesitações, falhas e sucessos. E, espero, ensinará que nada é tão claro e simples quanto pensávamos antes e que nada do que aceitamos foi jamais provado. É preciso abandonar nossa arrogância usual de que nós, os modernos, chegamos à verdade, para que se torne possível captar o outro lado da história. Só assim será possível ver que aqueles que negavam o vazio não eram tolos ou louco. (MARTINS, 1989a, p. 9).

\section{Referências}

ALFONSO-GOLDFARB, A. M. O que é história da ciência. São Paulo: Brasiliense, 1994. ALLCHIN, D. Scientific myth-conceptions. Science \& Education, n. 87, v. 3, p. 329-351, 2003.

BALDINATO, J. O; PORTO, P. A. Variações da história da ciência no ensino de ciências. In: ENCONTRO NACIONAL DE PESQUISA EM EDUCAÇÃO EM CIÊNCIAS, 6., 2008, Belo Horizonte. Anais... Belo Horizonte: ABRAPEC, 2008. 
BATISTA, R. P.; MOHR, A.; FERRARI, N. Análise da história da ciência em livros didáticos do ensino fundamental em Santa Catarina. In: ENCONTRO NACIONAL DE PESQUISA EM EDUCAÇÃO EM CIÊNCIAS. 2007, Florianópolis, SC. Anais do VI ENPEC. ABRAPEC, 2007.

BOAS, A. V.; SILVA, M. R.; PASSOS, M. M.; ARRUDA, S. M. História da ciência e natureza da ciência: debates e consensos. Caderno Brasileiro de Ensino de Física, v. 30, n. 2, p. 287-322, ago. 2013.

BONJORNO J. R; BONJORNO R. F. S. A; BONJORNO V; RAMOS C. M; PRADO E. P; CASSIMIRO R. Física Mecânica 1. São Paulo: Editora FTD, 2013.

BRASIL. Ministério da Educação. Parâmetros Curriculares Nacionais para o Ensino Médio. Brasília: MEC/SEMTEC, 2000.

BRASIL. Diretrizes Curriculares Nacionais para a Educação Básica. Brasília: MEC/SEMTEC, 2013.

BRASIL. Base Nacional Comum Curricular. Brasília: MEC, 2015.

BRASIL. Orientações curriculares para o ensino médio. Ciências da natureza, matemática e suas tecnologias. Brasília: MEC/SEMTEC, 2006.

BRASIL. PNLD/2017. Edital de convocação para inscrição no processo de avaliação e seleção de obras didáticas para o Programa Nacional do Livro Didático 2017 - Ensino Médio.

BRINCKMANN, C. Formação de professores que atuam na disciplina de Física e a História da Ciência no ensino médio do meio oeste de Santa Catarina. Dissertação (Mestrado em Educação). Universidade do Oeste de Santa Catarina, 2008.

DIAS, P. M. C. A. (im) Pertinência da História ao Aprendizado da Física: um estudo de caso. Revista Brasileira de Ensino de Física, v. 23, n. 2, p. 226-235, 2001.

DOCA, R. H; BISCUELA, G. J; BÔAS, N.V. Física, 1. São Paulo: Saraiva, 2010.

DUARTE, M. C. A história da ciência na prática de professores portugueses: implicações para a formação de professores de ciências. Ciência \& Educação, v. 10, n. 3, p. 317-331, 2004.

FERRARO, N. G; SOARES, P. T. Os fundamentos da Física. São Paulo: Moderna, 2009.

FERRARO, N. G.; TORRES, C. M. A.; PENTEADO, P. C. M. Física. São Paulo, Editora Moderna, 2012.

FORATO, T. C. M.; MARTINS, R. A.; PIETROCOLA, M. Historiografia e Natureza da Ciência na sala de aula. Caderno Brasileiro de Ensino de Física, v. 28, n. 1, p. 27-59, 2011.

GASPAR, A. Física. São Paulo: Editora Ática, 2011. 
GIL PÉREZ, D.; MONTORO, I. F.; CARRACOSA, J. A.; CACHAPUZ, A. C.; PRAIA, J. Para uma imagem não deformada do trabalho científico. Ciência \& Educação, v. 7, n. 2, p. 125-153, 2001.

GONÇALVES FILHO, A.; TOSCANO, C. Física: interação e tecnologia. Volume 1. São Paulo: Leya, 2013.

GOULART, S. M. História da ciência: elo da dimensão transdisciplinar no processo de formação de professores de ciências. In: LIBÂNEO, J. C.; SANTOS, A. (Orgs.). Educação na era do conhecimento em rede e transdisciplinaridade. Campinas: Alínea, 2005. p. 203-213.

GRANT, E. Much ado about nothing: theories of space and vacuum from the Middle Ages to the Scientific Revolution. Cambridge: Cambridge University Press, 1981.

GUERRA, A. A identidade e o diálogo como possibilidade de superação da controvérsia entre educadores e historiadores da ciência. In: CAMARGO, S.; GENOVESE, L. G.;

DRUMMOND, J. M. H. F.; QUEIROZ, G. R.; NICOT, Y.; NASCIMENTO, S. S. (Org.). Controvérsias na Pesquisa em Ensino de Física. São Paulo: Livraria da Física, 2014. p. 129142.

KANTOR, C.; PAOLIELLO JUNIOR, LILIO A.; MENEZES, L. C.; BONETTI, M. C.; CANATO JUNIOR, O.; ALVES, V. Quanta Física. São Paulo: Editora PD, 2010.

KRAGH, H. An introduction to the Historiography of Science. Cambridge: Cambridge University Press, 1987.

LONGUINI, M. D.; NARDI, R. Origens históricas e considerações acerca do conceito de pressão atmosférica. Caderno Brasileiro de Ensino de Física, v. 19, n.1, p. 67-78, 2002.

MAGIE, W. F. A source book in Physics. Cambridge, MA: Harvard University Press, 1969.

MARTINS, A. F. P. História e filosofia da ciência no ensino: Há muitas pedras nesse caminho. Caderno Brasileiro de Ensino de Física, v. 24, n.1, p. 112-131, 2007.

MARTINS, L. A-C. P. História da ciência, objetos, métodos e problemas. Ciência \& Educação, v. 11, n. 2, p. 305-317, 2005.

MARTINS, L. A-C P.; BRITO, A. P. O.P. M. A História da Ciência e o ensino de genética no nível médio: um estudo de caso. In: SILVA, C.C. Estudos de História e Filosofia das Ciências: subsídios para aplicação no ensino. São Paulo: Livraria da Física, 2006. p. $245-$ 264.

MARTINS, R. A. O vácuo e a pressão atmosférica, da Antiguidade a Pascal. Cadernos de História e Filosofia da Ciência, v. 1, n. 3, p. 9-48, 1989a.

MARTINS, R. A. Tratados Físicos de Blaise Pascal. Seleção e tradução. Cadernos de História e Filosofia da Ciência, v. 1, n. 3, p. 49-167, 1989b.

MARTINS, R. A. Ciência versus historiografia: os diferentes níveis discursivos nas obras sobre história da ciência. In: ALFONSO-GOLDFARB, A. M.; BELTRAN, M. H. R. (orgs). 
Escrevendo a História da Ciência: tendências, propostas e discussões historiográficas. São Paulo: EDUC/Livraria Editora da Física, 2004. p. 115-145.

MARTINS, R. A. Introdução: A história das ciências e seus usos na educação. In: SILVA, C. C. Estudos de história e filosofia das ciências: subsídios para aplicação no ensino. São Paulo: Livraria da Física, 2006. p. xxi-xxiv.

MATTHEWS, M. R. Science teaching: the role of History and Philosophy of Science. New York, London: Routledge, 1994.

MATTHEWS, M. R. História, Filosofia e Ensino de Ciências: a tendência atual de reaproximação. Caderno Catarinense de Ensino de Física, v. 12, n. 3, p. 164-214, 1995.

MÁXIMO, A.; ALVARENGA, B. Física: volume único. Coleção De olho no mundo do trabalho. São Paulo: Editora Scipione, 2003.

MÁXIMO, A.; ALVARENGA, B. Física Contexto \& Aplicações. Volume 1. São Paulo: Editora Scipione, 2011.

OLIVEIRA, M.P. P; POGIBIN, A.; OLIVEIRA, R.C.A.; ROMERO, T. R. L. Física em Contexto: pessoal, social e histórico. Movimento, força, astronomia. São Paulo: FTD, 2011.

OLIVEIRA, R. A.; SILVA. A. P. B. A História da Ciência no Ensino: diferentes enfoques e suas implicações na compreensão da Ciência. In: ENCONTRO NACIONAL DE PESQUISA EM EDUCAÇÃO EM CIÊNCIAS. 2011, Campinas, SP. Anais do VIII ENPEC. ABRAPEC, 2011.

PAGLIARINI, C. R.; SILVA, C. C. A Estrutura dos Mitos Históricos nos Livros de Física. In: ENCONTRO DE PESQUISA EM ENSINO DE FÍSICA, 10, 2006, Londrina, PR.

PARANÁ, D. N. S. Física Mecânica. São Paulo: Editora Ática, 1999.

PASCAL, B. Récit de la grande experiénce de l'equilibre des liqueurs. Paris: Chez Charles Saureux, 1648.

PEDUZZI, L. O. Q. Sobre a utilização didática da História da Ciência. In: PIETROCOLA, M. Ensino de física: conteúdo e epistemologia numa concepção integradora. Florianópolis: Ed. da UFSC, 2001. p. 151-170.

PEDUZZI, L. O. Q. Sobre a História e o Ensino da Física. In: Evolução dos Conceitos da Física. Florianópolis: Ed. da UFSC, 2011. p. 9-19.

PRESTES, M. E.; CALDEIRA, A. M. Introdução. A importância da história da ciência na educação científica. Filosofia e História da Biologia, v. 4, p. 1-16, 2009.

SANT'ANNA, B.; MARTINI, G.; REIS, H. C.; SPINELLI, W. Conexões com a Física. Volume 1. São Paulo: Editora Moderna, 2010.

SANT'ANNA, B.; MARTINI, G.; REIS, H. C.; SPINELLI, W. Conexões com a Física. Volume 1. São Paulo: Editora Moderna, 2013. 
SAMPAIO, J. CALÇADA, C. Física. São Paulo: Atual, 2008.

SILVEIRA, F. A Filosofia da Ciência e o Ensino de Ciências. Em Aberto, n.11, v. 55, p. 36$41,1992$.

STEFANOVITS A. Ser Protagonista: Física. São Paulo: Edições SM, 2013.

TORRES, C.; FERRARO, N.; SOARES, P. Física - Ciência e Tecnologia. São Paulo: Moderna, 2010.

VIDAL, P. H. O.; PORTO, P. A. A história da ciência nos livros didáticos de química do PNLEM 2007. Ciência \& Educação, v.18, n. 2, p. 291-308, 2012.

VIDEIRA, A. A. P. Historiografia e história da ciência. Escritos, v. 1, p. 111-158, 2007.

YAMAMOTO, K.; FUKE, L. F. Física para o Ensino Médio 1. São Paulo: Saraiva, 2013.

\section{SOBRE OS AUTORES}

JULIANA M. HIDALGO. É bacharel em Física pela UNICAMP, mestre em História da Ciência e doutora em Filosofia pela PUC-SP. Realizou estágios de pós-doutoramento na UNICAMP e na PUC-SP. Atua como docente no Departamento de Física Teórica e Experimental da UFRN. É professora permanente no Programa de Pós-Graduação em Ensino de Ciências Naturais e Matemática e no Programa de Pós-graduação em Ensino de Física, ambos na UFRN.

JARDES M. ALVES. É licenciado em Física pela UFRN e mestrando em Ensino de Física pelo Programa de Pós-graduação em Ensino de Física da UFRN.

FÁBIO DE ABREU SOUZA. É licenciado em Física pela UFRN e mestrando em Ensino de Ciências pelo Programa de Pós-Graduação em Ensino de Ciências Naturais e Matemática da UFRN. Atua como professor na rede pública do Rio Grande do Norte.

DANIEL DE MEDEIROS QUEIROZ. É licenciado em Física pela UFRN e mestrando em Ensino de Ciências pelo Programa de Pós-Graduação em Ensino de Ciências Naturais e Matemática da UFRN. Atua como professor na rede pública do Rio Grande do Norte.

Recebido: 11 de fevereiro de 2017.

Revisado: 21 de setembro de 2017.

Aceito: 08 de fevereiro de 2018. 